\title{
Reduced bone mineral content and density in neurofibromatosis type 1 and its association with nutrient intake
}

(iD) Marcio Leandro Ribeiro de Souza ${ }^{1}$

(iD) Ann Kristine Jansen ${ }^{1}$

(DL Luiz Oswaldo Carneiro Rodrigues ${ }^{1}$

(D) Darlene Larissa de Souza Vilela ${ }^{1}$

(iD) Adriana Maria Kakehasi ${ }^{1}$

(iD) Aline Stangherlin Martins ${ }^{1}$

(D) Juliana Ferreira de Souza ${ }^{1}$

(iD) Nilton Alves de Rezende

1. Universidade Federal de Minas Gerais, Belo Horizonte, MG Brasil.

http://dx.doi.org/10.1590/1806-9282.66.5.666

\section{SUMMARY}

BACKGROUND: Neurofibromatosis type 1 (NF1) is an autosomal dominant genetic disease characterized by multisystem involvement including low bone mineral density (BMD).

OBJECTIVE: To assess the bone phenotype of individuals with NF1 and verify its association with nutrient intake.

METHODS: Twenty-six adults with NF1 underwent bone phenotype assessments using dual-energy X-ray absorptiometry (DXA) and food intake evaluations. They were compared to 26 unaffected matched control patients. Weight, height, and waist circumference (WC) were measured. DXA provided total body, spine, and hip BMDs and bone mineral content (BMC) for all patients. Food intake was evaluated for energy, macro- and micro-nutrients.

RESULTS: Height (1.68 $\pm 0.1 ; 1.61 \pm 0.1 \mathrm{~cm} ; P=0.003)$ and BMC $(2.3 \pm 0.4 ; 2.0 \pm 0.5 \mathrm{~kg} ; P=0.046)$ were lower in the NF1 group. Individuals with NF1 also presented lower total body and spine BMDs $(\mathrm{g} / \mathrm{cm} 2)(1.1 \pm 0.1,1.0 \pm 0.1, P=0.036 ; 1.0 \pm 0.1,0.9 \pm 0.1 ; P=0.015$, respectively). The frequency of total body bone mass below the expected level for patients' ages was higher in the NF1 group (7.7\%; $34.6 \%, P=0.016)$. There were no differences in energy consumption. No correlations between BMC and BMD with nutrient intake were observed in the NF1 group.

CONCLUSIONS: The NF1 group presented lower BMCs and BMDs. Although a lower consumption of calcium, iron, and vitamin A, and a higher intake of sodium and omega- 6 were observed, there was no relationship between bone phenotype and nutrient intake.

KEYWORDS: Neurofibromatosis 1. Nutrients. Eating. Bone density. Bone development.

\section{INTRODUCTION}

Neurofibromatosis type 1 (NF1) is the most prevalent in a group of three genetic diseases called Neurofibromatoses. It is caused by inherited or de novo mutations on chromosome 17, resulting in reduced neurofibromin synthesis, which subsequently reduces tumor suppression' ${ }^{1}$. The diagnostic criteria for NF1 
are clinical and established by the National Institute of Health (NIH) Consensus ${ }^{2}$. The most common clinical features of NF1 are café au lait spots, dermal and plexiform neurofibromas, Lisch nodules, axillary and/ or inguinal freckling, and some typical bone dysplasia $^{1,3}$. NF1 can also exhibit multisystemic involvement, including bone disorders $\mathbf{s}^{1,3,4}$.

Some studies have shown a reduction of bone mineral density (BMD) and an increase of osteoporosis and osteopenia in individuals with NF1, although the mechanism responsible for these alterations is not well known ${ }^{4}$. Some experimental studies suggest that neurofibromin plays a central role in these alterations since it adversely regulates the function of Ras proteins and controls cell proliferation, differentiation, and apoptosis in bone tissue ${ }^{5-8}$. The majority of studies evaluating BMD in NF1 were performed in children, demonstrating a reduction of bone mass in this population when compared with healthy controls ${ }^{8}$. The few studies conducted in adults also confirm these changes ${ }^{9-11}$.

Poor nutrition and insufficient intake of nutrients related to bone metabolism are also part of the risk factors for the development of osteopenia and osteoporosis $^{12}$. Nutritional studies in NF1 are scarce and have only recently begun. Previously, our group published a cross-sectional study of 60 adults with NF1 and showed that NF1 individuals had an unhealthy diet, rich in fats and sodium and lacking in fiber and micronutrients, especially magnesium, vitamin D, calcium, and pyridoxine ${ }^{13}$.

A recent search of the MEDLINE, SCOPUS, Lilacs, and SciELO databases did not identify any studies involving the bone characteristics of Brazilian adults with NF1, and no studies were found that researched the association of bone status with nutrient consumption. Thus, using gold-standard methodologies for bone evaluation, the present study aimed to investigate bone phenotypes in individuals with NF1 and verify its associations with nutrient intake.

\section{METHODS}

\section{Ethical Statement}

This study complies with the Declaration of Helsinki and was approved by the Research Ethics Committee of our institution under protocol number CAAE-03005812.6.0000.5149. All subjects provided written informed consent before admission to the study. The study protocol did not interfere with any medical procedures.

\section{Sample}

This case-control study included NF1 individuals $>18$ years old who were evaluated in a Brazilian Neurofibromatosis Outpatient Reference Center. Patients were excluded based on: musculoskeletal limitations, the presence of diseases that required a specific diet or food consumption, neoplasms, hypothyroidism, weight loss $\geq 10 \%$ in the last six months, and use of medications that might compromise nutritional assessments or BMD. We also excluded men $>50$ years old and postmenopausal women because they have a high risk of osteoporosis. The NF1 group was compared to unaffected controls (1:1) and matched by sex, age, body mass index (BMI), and physical activity levels evaluated by the International Physical Activity Questionnaire (IPAQ) short version. The control group included individuals with similar socioeconomic characteristics (income and education level), such as neighbors, friends, or relatives who do not live in the same household. After performing a pre-test with ten individuals from each study group, a power calculation was performed, and it was determined that to attain a test power of $80 \%$, a minimum of 24 individuals in each group was required.

\section{Data Collection}

Bone characteristics were assessed by dual-energy X-ray absorptiometry (DXA), using the Discovery W Hologic ${ }^{\circledR}$ device (Bedford, MA, USA), software version 3.3.0. A qualified professional interpreted the results. Total body measurements lasted six minutes and were performed with the individuals lying in a supine position after removing all metal fittings as recommended by the manufacturer. For spine analyses, individuals remained lying down, with their legs supported by a box that aligned their pelvises and the lower portions of their lumbar spines. In the femoral analyses, individuals were placed in a supine position with their feet strapped to a triangular support allowing internal rotation of the hip ${ }^{12,14}$. All these placements followed the manufacturer's guidelines. The room was equipped with air conditioning and the room temperature was maintained constant during all the measurements.

Anthropometric measurements were also evaluated to characterize our population and included: weight, height, body mass index (BMI), and waist circumference (WC). These measurements followed the protocol proposed by the World Health Organization (WHO) ${ }^{15,16}$. The BMI categories used in this study were: normal weight (BMI $18.5-25 \mathrm{~kg} / \mathrm{m}^{2}$ ), 
underweight (BMI $\left.<18.5 \mathrm{~kg} / \mathrm{m}^{2}\right)$, and overweight (BMI $\left.\geq 25.0 \mathrm{~kg} / \mathrm{m}^{2}\right)^{15}$.

Food intake was obtained using three self-reported $24 \mathrm{~h}$ dietary recall surveys $(24 \mathrm{HR})$ on three non-consecutive days (2 days during the week and, as a non-typical day, 1 day during the weekend), in accordance with the recommendations of the Institute of Medicine ${ }^{17}$, which proposes that at least two $24 \mathrm{HRs}$ be used for similar studies. The interviewer had been trained in how to record portion sizes and the subjects provided detailed descriptions of all consumed food and drink, as well as the cooking methods, ingredients, and the use of salt and oil during their preparation. Potential confounding variables were evaluated by questioning the subjects regarding food quantities, added ingredients, and the brands that they consumed.

The amounts of each nutrient consumed were converted into grams. Any consumption of dietary supplements reported by a participant was also included in the nutrient analysis. The mean 3-day values were used in our analyses. Energy, macro- and micronutrients were evaluated in our study.

\section{Statistical Analyses}

All statistical analyses were conducted using the Statistical Package for Social Sciences (SPSS ${ }^{\circledR}$ ) version 19.0 for Windows (SPSS Inc., Chicago, IL, USA). The Kolmogorov-Smirnov test was used to evaluate normality and determine the appropriate statistical test. Qualitative variables were described using absolute and relative (percentage) frequencies. Grouped comparisons of qualitative variables were performed using McNemar's or chi-squared tests. Quantitative variables with a normal distribution were expressed as mean and standard deviation and compared using the paired Student's $t$-test. Quantitative variables that were not normally distributed were presented as medians with minimum and maximum values and compared using the nonparametric Wilcoxon test. Correlations were evaluated using Pearson's test for normal distributions or Spearman's correlation for non-normal distributions. $P$-values $<0.05$ were considered statistically significant.

\section{RESULTS}

Twenty-nine individuals with NF1 were included in this study, and three were excluded (one 51-year-old man with hypothyroidism, and two postmenopausal women: 55 and 57 years old). The remaining 26 subjects were comprised of 12 women (46.2\%) and 14 men (53.8\%). The NF1 group was compared to 26 unaffected controls, matched by sex, age, BMI, and physical activity levels.

Demographic, anthropometric, and bone characteristics data are listed in Table 1. There were no differences for age, weight, BMI, and WC $(P=0.316, P=0.175$, $P=0.768$ and $P=0.807$, respectively). Statistically, the NF1 group was shorter in stature $(P=0.003)$. For bone parameters, BMCs were lower in the NF1 group compared to the controls $(P=0.046)$. In addition, the NF1 group had lower total body $(P=0.036)$ and spine $(P=0.015)$ BMDs ( $g /$ $\left.\mathrm{cm}^{2}\right)$ and lower total body $(P=0.049)$ and spine $(P=0.025)$ Z-scores. For the total body, the prevalence of subjects with bone mass below the expected level for their ages was higher in the NF1 group (34.6\%) compared to the controls (7.7\%) ( $P=0.016)$. No differences were observed in hip parameters.

Comparing nutrient intakes (Table 2), there were no differences in energy and macronutrient (carbohydrate, protein, and fat) consumption, except for polyunsaturated fats $(P=0.013)$, especially omega- $6(P=0.008)$. The NF1 group also consumed higher amounts of sodium $(P=0.018)$ and lower amounts of calcium $(P=0.038)$, iron $(P=0.042)$, and vitamin A $(P=0.038)$.

Figure 1 presents the correlations between BMC and total BMD with nutrient intake parameters. In the control group, BMC and total BMD presented a positive weak correlation with carbohydrate intake. In the NF1 group, there was no association between $\mathrm{BMC}$ and BMD with nutrient intake.

\section{DISCUSSION}

In our study, individuals with NF1 showed lower BMCs and BMDs for their total body and spine and a higher prevalence of bone mass below the expected level for their age in their total body. No previous studies were found verifying the association between bone parameters and nutrient intake in NF1 individuals.

Lower BMDs in adults with NF1 have been demonstrated in other studies. Lammert et al. ${ }^{11}$ evaluated 104 adults with NF1 aged 20 to 80 years. Using quantitative ultrasonography, they found lower BMDs in adults with NF1 when comparing their results to reference values for a population not affected by the disease (no control group was used). In another study using DXAs with 26 NF1 subjects aged 24-73 years, the authors found lower BMDs and BMCs in the NF1 
TABLE 1. DEMOGRAPHIC, ANTHROPOMETRIC, AND BONE CHARACTERISTICS FOR EACH GROUP

\begin{tabular}{|c|c|c|c|}
\hline Parameters & Control $(n=26)$ & $N F 1(n=26)$ & P-value* \\
\hline Age (years) & $32.92(6.14)$ & $34.31(6.05)$ & 0.316 \\
\hline Weight (kg) & $69.08(14.11)$ & $62.54(16.99)$ & 0.175 \\
\hline Height (m) & $1.68(0.08)$ & $1.61(0.10)$ & 0.003 \\
\hline $\mathrm{BMI}\left(\mathrm{kg} / \mathrm{m}^{2}\right)$ & $24.28(3.64)$ & $23.88(4.83)$ & 0.768 \\
\hline Waist circumference $(\mathrm{cm})$ & $82.37(11.43)$ & $81.39(14.62)$ & 0.807 \\
\hline $\mathrm{BMC}(\mathrm{kg})$ & $2.29(0.43)$ & $2.03(0.47)$ & 0.046 \\
\hline \multicolumn{4}{|l|}{ TOTAL BODY } \\
\hline BMD total body $\left(\mathrm{g} / \mathrm{cm}^{2}\right)$ & $1.10(0.10)$ & $1.04(0.10)$ & 0.036 \\
\hline BMD total body - Z-score & $-0.75(0.93)$ & $-1.35(1.12)$ & 0.049 \\
\hline Categorization - n (\%) & & & 0.016 \\
\hline Normal bone mass & $24(92.3)$ & $17(65.4)$ & \\
\hline Bone mass below the expected level for age & $2(7.7)$ & $9(34.6)$ & \\
\hline \multicolumn{4}{|l|}{ SPINE } \\
\hline BMD spine $\left(\mathrm{g} / \mathrm{cm}^{2}\right)$ & $1.00(0.08)$ & $0.91(0.14)$ & 0.015 \\
\hline BMD spine - Z-score & $-0.69(0.92)$ & $-1.39(1.24)$ & 0.025 \\
\hline Categorization - n (\%) & & & 0.070 \\
\hline Normal bone mass & $24(92.3)$ & $18(69.2)$ & \\
\hline Bone mass below the expected level for age & $2(7.7)$ & $8(30.8)$ & \\
\hline \multicolumn{4}{|l|}{ HIP (femoral neck) } \\
\hline BMD Hip (femoral neck) (g/cm²) & $0.85(0.15)$ & $0.77(0.12)$ & 0.106 \\
\hline BMD Hip (femoral neck) - Z-score & $-0.26(1.16)$ & $-0.74(0.96)$ & 0.165 \\
\hline Categorization - n (\%) & & & 1.000 \\
\hline Normal bone mass & $24(92.3)$ & $23(88.5)$ & \\
\hline Bone mass below the expected level for age & $2(7.7)$ & $3(11.5)$ & \\
\hline \multicolumn{4}{|l|}{ HIP (total femoral) } \\
\hline BMD Hip (total femoral) (g/cm²) & $0.94(0.13)$ & $0.90(0.13)$ & 0.309 \\
\hline BMD Hip (total femoral) - Z-score & $-0.32(0.91)$ & $-0.56(0.97)$ & 0.409 \\
\hline Categorization - n (\%) & & & 0.705 \\
\hline Normal bone mass & $26(100)$ & $23(88.5)$ & \\
\hline Bone mass below the expected level for age & 0 & $3(11.5)$ & \\
\hline
\end{tabular}

Note: NF1: Neurofibromatosis type 1; SD: standard deviation; BMI: body mass index; BMC: bone mineral content; BMD: bone mineral density; kg: kilogram; g: gram; m: meter;

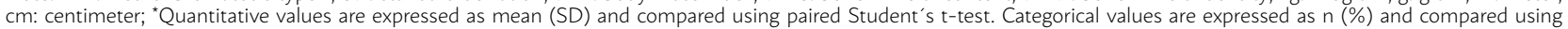
McNemar's or chi-squared tests.

group compared to controls ${ }^{10}$. Illés et al. ${ }^{9}$ showed lower spine BMDs than expected for their age in 12 individuals with NF1, ranging from 7.6 to 42.7 years, assessed by Z-scores using DXA, but these results were not compared to a control group.

In our study, there was no difference in hip BMDs (total or femoral). A statistical difference was only found for the spine and total body BMDs. This result follows the trend of bone metabolism in young individuals in whom the lumbar spine shows precocious bone loss since this is a region with more trabecular bone. In the femur, with a predominance of cortical bone, this loss is slower ${ }^{18}$.

Our hypotheses to explain the lower bone mass in NF1 are summarized in Figure 2 and will be discussed in sequence. These bone changes in NF1 may be related to the deficiency of neurofibromin and, consequently, greater activation of Ras proteins, which control cell proliferation, differentiation, and apoptosis in bone tissue. In mice with NF1, the activity of osteoclasts was higher due to an increase in Ras activation ${ }^{5-8}$. The Ras pathway may be associated with bone alterations in NF1, since in other RASophaties, such as Costello's Syndrome, bone mineral density is also reduced ${ }^{19}$.

Another possible explanation for the lower BMCs and BMDs may be related to calcidiol (25-OH-D3) levels. Vitamin D plays an important role in bone health, since reduced levels of this vitamin decrease intestinal calcium absorption, elevate parathyroid hormone, and increase bone resorption ${ }^{20}$. Vitamin D levels were not investigated in our study.

Poor nutrition and insufficient intake of nutrients related to bone metabolism are part of the risk factors for the development of osteopenia and osteoporosis ${ }^{12}$. 
TABLE 2. NUTRIENT INTAKE: ENERGY, MACRO- AND MICRO-NUTRIENT CONSUMPTION FOR EACH GROUP

\begin{tabular}{|c|c|c|c|}
\hline Parameters & Control $(n=26)$ & $\operatorname{NF1}(n=26)$ & P-value \\
\hline Energy (kcal) & $2,104.4(1,177.4-3,344.3)$ & 2,202.6 (1,257.2 - 3,000.0) & $0.240 \#$ \\
\hline Energy (kcal/kg/d) & $29.6(16.0-69.0)$ & $35.9(20.6-67.5)$ & $0.069^{*}$ \\
\hline Carbohydrate (g) & $227.8(106.6-392.0)$ & $240.4(138.9-392.3)$ & 0.439\# \\
\hline Carbohydrate (g/kg/d) & $3.5(1.7-8.0)$ & $4.1(1.9-8.4)$ & $0.205 \#$ \\
\hline Protein (g) & $91.8(31.8-134.0)$ & $88.1(50.7-179.3)$ & $0.874 \#$ \\
\hline Protein (g/kg/d) & $1.4(0.5-2.9)$ & $1.5(0.8-2.9)$ & $0.317 \#$ \\
\hline Fat (g) & $81.3(36.5-144.9)$ & $90.9(50.1-163.5)$ & $0.172 \#$ \\
\hline Fat $(\mathrm{g} / \mathrm{kg} / \mathrm{d})$ & $1.2(0.5-2.9)$ & $1.4(0.7-3.0)$ & $0.096^{\star}$ \\
\hline Fiber (g) & $18.8(10.3-42.1)$ & $19.8(8.1-44.1)$ & 0.978\# \\
\hline Saturated FA (g) & $30.6(11.2-56.7)$ & $30.3(16.7-55.5)$ & 0.981\# \\
\hline Monounsaturated FA (g) & $31.9(11.2-47.9)$ & $31.0(17.1-48.5)$ & $0.502 \#$ \\
\hline Polyunsaturated FA (g) & $22.2(9.9-43.6)$ & $29.5(9.2-55.1)$ & $0.013 \#$ \\
\hline Linolenic Acid (w3) (g) & $2.8(1.0-4.6)$ & $3.3(1.1-6.6)$ & $0.120 \#$ \\
\hline Linoleic Acid (w6) (g) & $19.1(7.6-36.8)$ & $26.5(8.0-48.3)$ & $0.008 \#$ \\
\hline Cholesterol (mg) & $321.3(138.1-652.0)$ & $296.1(133.1-630.6)$ & $0.319 \#$ \\
\hline Calcium (mg) & $623.2(159.1-2,563.8)$ & $439.0(133.4-1,364.2)$ & $0.038^{*}$ \\
\hline Magnesium (mg) & $244.0(84.0-480.0)$ & $233.2(145.3-369.0)$ & $0.857 \#$ \\
\hline Manganese (mg) & $2.6(1.3-7.1)$ & $2.2(1.3-5.3)$ & $0.280^{*}$ \\
\hline Phosphorus (mg) & 1,164.0 (569.3 - 2,545.3) & 1,108.4 (634.0 - 2,248.2) & $0.474 \#$ \\
\hline Iron (mg) & $10.2(5.3-18.7)$ & $8.8(5.3-12.2)$ & $0.042 \#$ \\
\hline Sodium (mg) & 3,010.1 (1,696.0 - 5,570.2) & 3,849.9 (1,678.7 - 9,017.2) & 0.018\# \\
\hline Potassium (mg) & $2,465.4(772.9-4,562.6)$ & $2,502.3(1,408.9-3,923.9)$ & $0.912 \#$ \\
\hline Copper (mg) & $0.9(0.5-1.7)$ & $0.9(0.5-3.4)$ & $0.980^{*}$ \\
\hline Zinc (mg) & $11.4(4.0-18.8)$ & $9.7(5.5-21.7)$ & $0.362 \#$ \\
\hline Thiamine (mg) & $1.4(0.6-4.5)$ & $1.3(0.7-10.0)$ & $0.799^{*}$ \\
\hline Riboflavin (mg) & $1.1(0.5-3.5)$ & $1.0(0.5-3.1)$ & $0.525^{*}$ \\
\hline Pyridoxine (mg) & $0.8(0.2-2.3)$ & $0.9(0.3-1.8)$ & $0.836 \#$ \\
\hline Niacin (mg) & $19.9(6.1-43.8)$ & $20.2(5.2-51.6)$ & 0.509\# \\
\hline Vitamin C (mg) & $58.7(9.7-1003.7)$ & $70.7(3.6-310.3)$ & $0.638^{*}$ \\
\hline Vitamin D (mcg) & $3.2(0.9-13.4)$ & $2.7(0.9-18.5)$ & $0.517^{\star}$ \\
\hline Vitamin A (mcg) & $541.4(154.5-1,357.4)$ & $402.2(183.2-2,250.5)$ & $0.038^{*}$ \\
\hline
\end{tabular}

Note: All values are expressed as median (minimum-maximum); NF1: Neurofibromatosis type 1; FA: fatty acid; kg: kilogram; kcal: kilocalories; d: day; g: gram; mg: milligram; mcg: microgram; \#: paired Student's test; ${ }^{*}$ : Wilcoxon test.

FIGURE 1. CORRELATIONS BETWEEN BONE MINERAL CONTENT AND TOTAL BODY BONE MINERAL DENSITY WITH NUTRIENTINTAKE

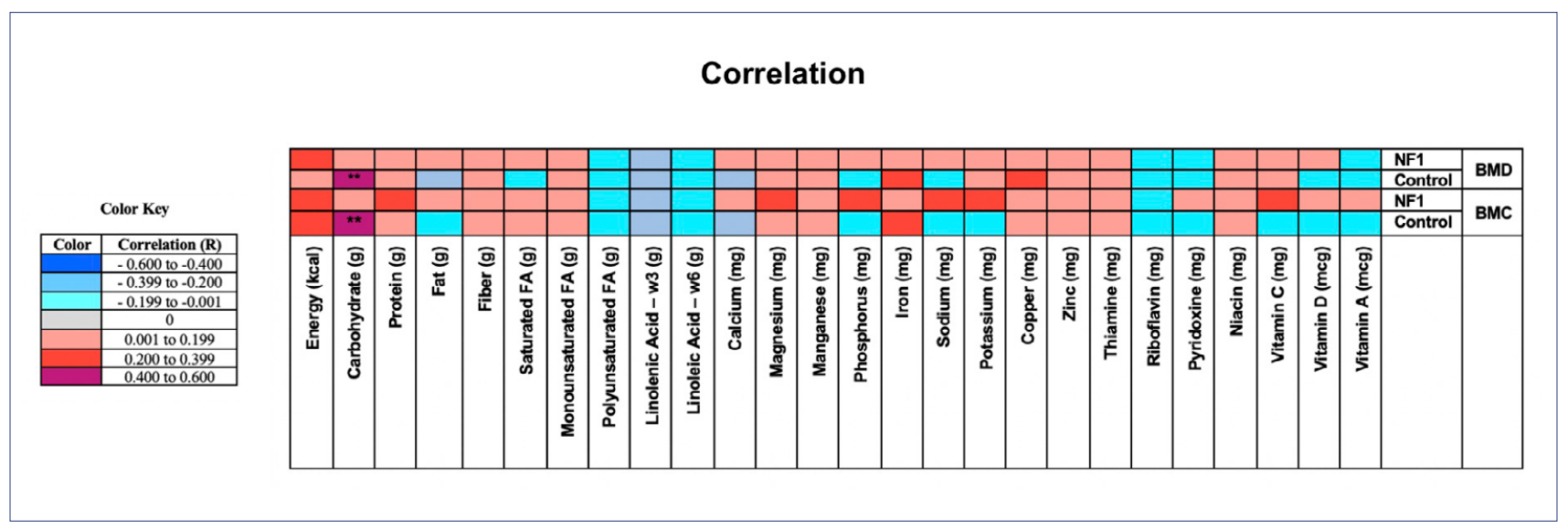

Note: NF1: Neurofibromatosis type 1; BMC: bone mineral content; BMD: total body bone mineral density; FA: fatty acid; kcal: kilocalorie; g: gram; mg: milligram; mcg: microgram; Pearson correlation for normal distributions and Spearman correlation for non-normal distributions. ${ }^{\star *}: p<0.05$. 
FIGURE 2. POSSIBLE HYPOTHESES TO EXPLAIN THE LOWER BONE MASS IN NF1

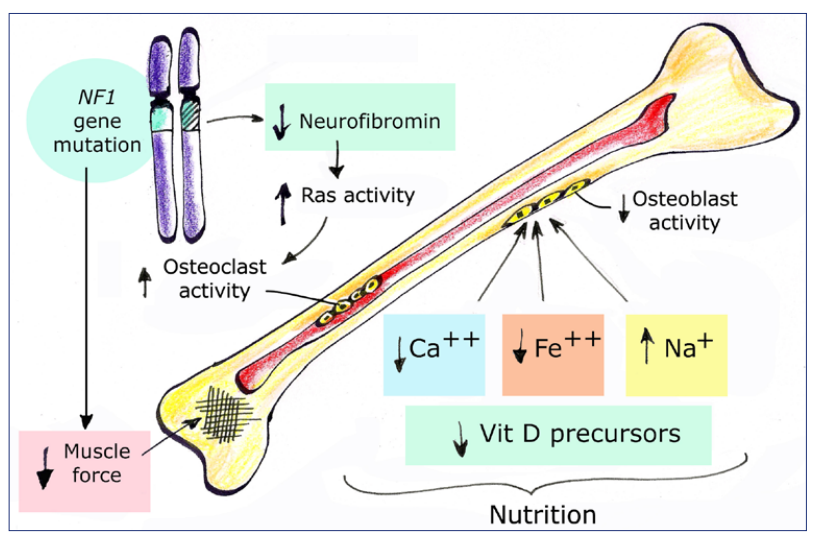

NF1: Neurofibromatosis type 1; Ca: calcium; Fe: iron; Na: sodium; Vit D: vitamin D.

In our study, the NF1 group consumed less calcium, iron, and vitamin $\mathrm{A}$, and higher amounts of sodium and omega-6: nutrients related to bone health. No differences were observed for energy and macronutrient intake, except for polyunsaturated fatty acid consumption. Other nutrients involved in bone health such as magnesium, manganese, phosphorus, potassium, vitamin D, zinc, and B-vitamins did not show differences between the two groups.

The median calcium intake for the NF1 group was approximately $439 \mathrm{mg}$ in our study, below the recommended dietary intake level (700 to 1,200 mg) for preventing osteopenia and osteoporosis ${ }^{12}$. Iron intake was also lower in individuals with NF1, and this mineral is used as a cofactor for enzymes involved in bone matrix synthesis (activation of lysyl hydroxylase) and in the synthesis of 25-hydroxy-cholecalciferol hydroxylase, which is responsible for the activation of vitamin $\mathrm{D}^{21,22}$.

Sodium intake was higher in subjects with NF1. High sodium intake may increase urinary calcium excretion, temporarily reducing serum calcium, resulting in increased parathyroid hormone and, consequently, increased bone resorption ${ }^{23}$. A higher intake of polyunsaturated fatty acids in the NF1 group, especially linoleic acid (omega-6) were also observed, probably due to the high consumption of vegetable oils, such as soybean oil. In humans with a Western dietary pattern, arachidonic acid, or its precursor linoleic acid, makes a significant contribution to the fatty acids present in the membrane phospholipids of cells involved in inflammation, which may be associated with bone diseases ${ }^{24,25}$.

Thus, in association with the genetic effects in NF1, dietary intake of nutrients could also have a role in the reduced spine and total body BMDs described in our study. However, even with the decrease in consumption of certain nutrients, it is important to note that no correlations between BMC with nutrient intake were found in the NF1 group. Even without any statistical associations, healthy nutrition and adequate intake of calcium, vitamin D, and protein are usually included in all recommendations or guidelines for maintaining bone health and delaying or preventing osteopenia and osteoporosis ${ }^{12}$.

Our study has some limitations. Current food consumption may not represent the subjects' consumption over the last few years, which is important since it is known that osteopenia/osteoporosis are slow-developing diseases. The external validity of this study must be viewed with caution, as the socio-economic characteristics and place of residence must be considered when extrapolating results to other nutritional studies in different countries. Randomization would be useful in improving the external validity of similar studies. Despite these limitations, this was the first study of bone characteristics in Brazilian adults with NF1. This was also the first study that evaluated the association between nutrient intake and bone parameters in NF1 individuals, although further controlled studies are needed to validate our results.

\section{CONCLUSIONS}

Individuals with NF1 presented lower BMCs and lower BMDs in their spines and total body when evaluated by DXA. Lower consumption of calcium, iron, and vitamin $\mathrm{A}$, and higher intakes of sodium and omega6 , all nutrients related to bone health, have also been observed in the NF1 group. However, no association between bone phenotypes and nutrient intake were found in our study. Further investigations including nutrition and bone characteristics in individuals with NF1 may help explain the mechanisms involved.

\section{Conflicts of interest}

All authors have no conflicts of interest.

\section{Funding}

The authors received financial support from three Brazilian government funding agencies: CAPES, National Council of Technological and Scientific Development - CNPq (\#471725/2013-7), and FAPEMIG (\#APQ-00928-11; \#PPM-00120-14). The funding sources did not influence in the design, analysis, writing, or decision to publish this study. 


\section{Author Contributions}

All authors (MLRS, AKJ, LORC, DLVS, AMK, ASM, JFS e NAR) conceived, planned, and performed the work leading to the report and interpreted the results. They also wrote, reviewed, and approved the final version.

\section{RESUMO}

INTRODUÇÃO: A Neurofibromatose tipo 1 (NF1) é uma doença genética autossômica dominante caracterizada por envolvimento neurocutâneo e multissistêmico, incluindo baixa densidade mineral óssea (DMO).

OBJETIVOS: Avaliar características ósseas em indivíduos com NF1 e verificar associação com a ingestão de nutrientes.

METODOLOGIA: 26 adultos com NF1 submeteram-se a avaliação dos parâmetros ósseos usando absorciometria com raios-X de dupla energia (DXA), além da avaliação da ingestão alimentar. O grupo NF1 foi comparado e pareado com 26 indivíduos sem a doença. Peso, estatura e circunferência da cintura foram avaliados. DXA forneceu o conteúdo mineral ósseo (CMO) e a DMO do corpo total, coluna e fêmur. A ingestão de calorias, macronutrientes e micronutrientes foi avaliada.

RESULTADOS: O grupo NF1 apresentou redução da estatura $(1,68 \pm 0,1 ; 1,61 \pm 0,1 \mathrm{~cm} ; P=0,003)$ e do $C M O(2,3 \pm 0,4 ; 2,0 \pm 0,5 \mathrm{~kg} ; P=0,046)$. Indivíduos com NF1 também apresentaram redução da DMO de corpo total e coluna (g/cm2) $(1,1 \pm 0,1,1,0 \pm 0,1, P=0,036 ; 1,0 \pm 0,1$ $0,9 \pm 0,1 ; P=0,015$, respectivamente). A frequência de indivíduos com massa óssea abaixo do esperado para a idade foi maior no grupo NF1 (7,7\%; 34,6\%, P=0,016). Não houve diferenças no consumo energético. Não houve correlação entre CMO e DMO com a ingestão de nutrientes no grupo NFT.

CONCLUSÕES: O grupo NF1 apresentou redução do CMO e da DMO. Apesar de menor consumo de cálcio, ferro e vitamina A, e maior consumo de sódio e ômega-6, não foi observada relação entre o fenótipo ósseo e a ingestão de nutrientes.

PALAVRAS-CHAVE: Neurofibromatose 1. Nutrientes. Ingestão de alimentos. Densidade óssea. Desenvolvimento ósseo.

\section{REFERENCES}

1. Rodrigues LO, Batista PB, Goloni-Bertollo EM, Souza-Costa D, Eliam L, Eliam M, et al. Neurofibromatoses: part 1 - diagnosis and differential diagnosis. Arq Neuropsiquiatr. 2014;72(3):241-50.

2. National Institutes of Health Consensus Development Conference Statement: neurofibromatosis. Bethesda, Md., USA, July 13-15, 1987. Neurofibromatosis. 1988;1(3):172-8.

3. Riccardi VM. Neurofibromatosis type 1 is a disorder of dysplasia: the importance of distinguishing features, consequences and complications. Birth Defects Res A Clin Mol Teratol. 2010;88(1):9-14

4. Batista PB, Bertollo EM, Costa DS, Eliam L, Cunha KS, Cunha-Melo JR, et al. Neurofibromatosis: part 2: clinical management. Arq Neuropsiquiatr. 2015;73(6):531-43.

5. Yang FC, Chen S, Robling AG, Yu X, Nebesio TD, Yan J, et al. Hyperactivation of p21ras and PI3k cooperate to alter murine and human neurofibromatosis type 1-haploinsufficient osteoclast functions. J Clin Invest. 2006;116(11):2880-91.

6. Wu X, Estwick SA, Chen S, Yu M, Ming W, Nebesio TD, et al. Neurofibromin plays a critical role in modulating osteoblast differentiation of mesenchymal stem/progenitor cells. Hum Mol Genet. 2006;15(19):2837-45.

7. Stevenson DA, Yan I, He Y, Li H, Liu Y, Zhang Q, et al. Multiple increased osteoclast functions in individuals with neurofibromatosis type 1. Am / Med Genet A. 2011;155A(5):1050-9.

8. Poyrazoğlu HG, Bas VN, Arslan A, Bastug F, Canpolat M, Per H, et al. Bone mineral density and bone metabolic markers' status in children with neurofibromatosis type 1. J Pediatr Endocrinol Metab. 2017;30(2):175-80.

9. Illés $T$, Halmai $V$, Jonge $T$, Dubousset |. Decreased bone mineral density in neurofibromatosis-1 patients with spinal deformities. Osteoporos Int. 2001;12(10):823-7.

10. Kuorilehto T, Pöyhönen M, Bloigu R, Heikkinen J, Väänänen $K$, Peltonen 1. Decreased bone mineral density and content in neurofibromatosis type 1: lowest local values are located in the load-carrying parts of the body. Osteoporos Int. 2005;16(8):928-36.

11. Lammert M, Kappler M, Mautner VF, Lammert K, Störkel S, Friedman JM et al. Decreased bone mineral density in patients with neurofibromatosis 1. Osteoporos Int. 2005;16(9):1161-6.

12. Compston |, Cooper A, Cooper C, Gittoes N, Gregson C, Harvey N et al; National Osteoporosis Guideline Group (NOGG). UK clinica guideline for the prevention and treatment of osteoporosis. Arch Osteoporos. 2017;12(1):43.

13. Souza ML, Jansen AK, Martins AS, Rodrigues LO, Rezende NA. Nutrient intake in neurofibromatosis type 1: a cross-sectional study. Nutrition. 2015;31(6):858-62.

14. Lewiecki EM, Binkley N, Morgan SL, Shuhart CR, Camargos BM, Carey J), et al; International Society for Clinical Densitometry. Best practices for dual-energy $X$-ray absorptiometry measurement and reporting: International Society for Clinical Densitometry Guidance. J Clin Densitom. 2016;19(2):127-40.

15. World Health Organization. Physical status: the use and interpretation of anthropometry. Report of a WHO Expert Committee. World Health Organ Tech Rep Ser. 1995;854:1-452.

16. World Health Organization. Waist circumference and waist-hip ratio. Report of a WHO Expert Consultation. Geneva: World Health Organization; 2011. 47p.

17. Institute of Medicine (US) Subcommittee on Interpretation and Uses of Dietary Reference Intakes; Institute of Medicine (US) Standing

18. Committee on the Scientific Evaluation of Dietary Reference Intakes. DRI dietary reference intakes: applications in dietary assessment. Washington: National Academy Press; 2000. 306p.

19. Corrêa PHS. Medida da densidade mineral óssea em dois sítios. Arq Bras Endocrinol Metab. 2003;47(1):3-4.

20. Stevenson DA, Schwarz EL, Carey JC, Viskochil DH, Hanson H, Bauer S, et al. Bone resorption in syndromes of the Ras/MAPK pathway. Clin Genet. 2011;80(6):566-73.

21. Wacker M, Holick MF. Vitamin D: effects on skeletal and extraskeletal health and the need for supplementation. Nutrients. 2013;5(1):111-48.

22. Zofková I, Nemcikova P, Matucha P. Trace elements and bone health. Clin Chem Lab Med. 2013;51(8):1555-61.

23. Higgs J, Derbyshire E, Styles K. Nutrition and osteoporosis prevention for the orthopaedic surgeon: a wholefoods approach. EFORT Open Rev. 2017;2(6):300-8

24. Park SM, loung JY, Cho YY, Sohn SY, Hur KY, Kim JH, et al. Effect of high dietary sodium on bone turnover markers and urinary calcium excretion in Korean postmenopausal women with low bone mass. Eur J Clin Nutr. 2015;69(3):361-6

25. Innes JK, Calder PC. Omega- 6 fatty acids and inflammation. Prostaglandins Leukot Essent Fatty Acids. 2018;132:41-8. 